\title{
Prevalence of obesity, overweight and central obesity among adolescent girls in national school in Batticaloa district, Sri Lanka
}

\author{
Dharshini Karuppiah ${ }^{1,}$ Mithusha Markandu ${ }^{1}$ \\ ${ }^{1}$ Diabetes and Endocrine unit, Teaching Hospital, Batticaloa.
}

\section{Abstract}

Introduction: The prevalence of childhood obesity has increased over the recent decades. Obesity is a major risk factor for chronic diseases and plays a central role in insulin resistance and metabolic syndrome.

Methods: The aim of the study was to assess the prevalence of obesity and abdominal obesity by means of body mass index (BMI) and waist-to-height ratio (WHtR) in adolescent girls in a National school in Batticaloa, Sri Lanka. Based on age and sex specific BMI percentiles (CDC Chart), the students were classified as underweight ( $<5^{\text {th }}$ percentile), normal weight $\left(5^{\text {th }}-<85^{\text {th }}\right.$ percentile), overweight $\left(85^{\text {th }}-<95^{\text {th }}\right.$ percentiles), and obese $\left(\geq 95^{\text {th }}\right.$ percentile). Central obesity was categorized as WHtR $\geq 0.5$. Adolescent girls (aged 14-19 years) attending the ten $\&$ twelve grades $(\mathrm{n}=310)$ in a girl's high school at Batticaloa were participated in the study.

Results: The prevalence of obesity and overweight were 5.5\% and $9.4 \%$ among the girls. The prevalence of central obesity was $21.6 \%$. Around $11.16 \%$ of girls in the normal weight group were centrally obese. There was a significant relationship between WHtR and BMI status $(\mathrm{P}=0.0001)$.

Conclusion: Our study provides evidence showing a high prevalence of overall and central obesity in adolescent girls in our population. We emphasize the need for further large-scale surveillance programs and preventive strategies in our population to reduce the incidence of obesity.

Keywords: Adolescent girls, central obesity, obesity, waist-height ratio

DOI: http://doi.org/10.4038/sjdem.v8i1.7347

Received: $13^{\text {th }}$ January 2018

Accepted revised version: 24th February 2018

Published: $9^{\text {th }}$ April 2018

Correspondence e-mail: kdharshinik@gmail.com

This is an open-access article distributed under the terms of the Creative Commons Attribution 4.0 International License, which permits unrestricted use, distribution and reproduction in any medium provided the original author and source are credited 
The prevalence of obesity among children and adolescents has increased dramatically over the recent decades (1). A high prevalence of adolescence obesity and overweight cases has been reported in India, Bangladesh and other developing countries (2, 3). Prevalence in Sri Lanka shows regional variation. A survey done in 2006 showed the prevalence of overweight was 3-5\% among urban children and $1.7 \%$ in children living at rural regions (4). There are reports of much higher prevalence of $14-15 \%$ among school children in Colombo metropolitan area (5).

Obesity is a major risk factor for chronic diseases and plays a central role in insulin resistance and metabolic syndrome (6). This confers a serious issue because of the health consequences in childhood and adolescence and also the greater risk of obesity and metabolic syndrome in adulthood (7). Body mass index (BMI) is widely used as a measure to evaluate the impact of obesity on cardiovascular and metabolic risk factors, both in children and adults. However, in children, BMI changes with age and therefore a single cut-off value may not be used to define obesity.

The World Health Organization emphasizes the assessment of BMI in children providing BMI for age and sex percentiles (8). Similarly, Centers for Disease Control and Prevention (CDC) has recommended defining childhood obesity and over-weight based on a BMI-for-age and sex above $85^{\text {th }}$ and $95^{\text {th }}$ percentiles (9). A high BMI for age has been reported to be associated with risk for biochemical abnormalities and adult obesity $(10,11)$.

Nevertheless, BMI is unable to differentiate muscle mass from bone and fat mass and also does not always relate to central obesity. Moreover, children and adolescents with a high proportion of visceral fat will suffer from severe metabolic complications (12). Some studies observed that Waist Height ratio (WHtR) provide better estimate of cardio vascular risk factors than BMI (13-21). Whereas other studies did not prove any difference between BMI, waist circumference (WC) and WHtR in relation to cardiometabolic risk (22-24). The WHtR takes into account children's height; a single cut-off point can likely be set for the ratio without age and gender difference bias (25). It has been shown to be a simple, non-invasive, and practical tool that correlates well with visceral fat and is easier to use (25-28).
A WHtR cut off point of 0.5 has been proposed as a simple means of indicating whether the amount of central adiposity is excessive and represents a health risk in children (25-30). Considering the scarcity of studies on obesity and central obesity in children and adolescents in this region of the country the present study was done to assess the prevalence of obesity and central obesity by means of BMI and WHtR in a girl's high school in Eastern province, Sri Lanka.

\section{Methods}

\section{Sample}

Adolescent girls (aged 14-18 years) attending the ten \& twelve grades $(\mathrm{n}=310)$ in Vincent Girls high school participated in the study. This study was carried out as part of "World Diabetes Day program 2017". The survey was conducted with the cooperation of school teachers, medical students, and staffs from Diabetic Centre, Teaching Hospital Batticaloa. Informed written consent was obtained by means of a signed letter from the school authority. Students were verbally informed about the study and consent was obtained. Questionnaires were filled by researchers and used for the data collection.

\section{Anthropometric measurements}

All the girls were examined by a trained team consisting of doctors, medical students and diabetic educators. The team had received training and had been standardized in the measurement assessments. The assessment was carried out during school hours as time allocated by the school authority. Body weight was measured by a bathroom scale wearing light clothes. Standing height was measured with stadiometer and measurement was done to the nearest 0.1 $\mathrm{cm}$. Waist circumference (WC) measured to the nearest 0.5 $\mathrm{cm}$ in duplicate according to standard conditions by placing a flexible tape midway between the lowest rib and the iliac crest. The tape did not squeeze or compress the skin and was parallel to the floor. The measurement was taken on, relaxed subjects after gentle expiration. BMI was calculated as the ratio between weight (in kilograms) and the square of height (in meters). WHtR was calculated as the ratio between waist and height both measured in centimetres.

\section{Healthy life style score}

We developed a healthy life score ranged from 0 to 40 (higher score indicative of healthier lifestyle) and included 2 components: diet and physical activity. 
Table 1: Baseline characteristics of the subjects

\begin{tabular}{lcc} 
& Mean & SD \\
\hline Age (years) & 15.97 & \pm 1.047 \\
Weight (kg) & 50.08 & \pm 10.75 \\
Height (m) & 156.60 & \pm 5.344 \\
BMI (kgm-2) & 20.44 & \pm 4.114 \\
WC (cm) & 71.12 & \pm 9.962 \\
WHtR & 0.45 & \pm 0.062 \\
Healthy lifestyle score & 26.37 & \pm 3.020 \\
\hline
\end{tabular}

\section{Cut-off values}

Based on age and sex specific BMI percentiles, the girls were classified as underweight $\left(<5^{\text {th }}\right.$ percentiles) normal weight $\left(5^{\text {th }}<85^{\text {th }}\right.$ percentiles $)$, overweight $\left(85^{\text {th }}-<95^{\text {th }}\right.$ percentiles), and obese ( $\geq 95^{\text {th }}$ percentile). A cut off of 0.5 was used to differentiate low WHtR from high WHtR (8, 9).

\section{Data analysis}

Data were processed using the Statistical Package for the Social Sciences (SPSS). Descriptive statistics was presented as mean \pm standard deviation score for normally distributed data. Chi-Square test was used to evaluate the relationship between WHtR with BMI.

\section{Results}

The baseline characteristics of the subjects were shown in table 1. Median age of the students was $15.97( \pm 1.047)$ years. Median BMI was 20.44( \pm 4.11$) \mathrm{Kgm}^{-2}$ and median WHtR was 0.45 ( \pm 0.06$)$. Total number of girls participated in the study was 310. Among them, $215(68.9 \%)$ were within normal weight category. The prevalence of overweight and Obesity were 9.4\% (29) and 5.5\% (17). Forty-nine girls $(15.8 \%)$ were in the under-weight group.

The prevalence of central obesity was $21.6 \% .11 .16 \%$ of girls in the normal weight group were centrally obese. In overweight girls, $86.2 \%$ and in the obese group, $100 \%$ had central obesity (Figure 1). There was significant relationship between WHtR and BMI status $(\mathrm{P}=0.00001)$. Majority of obese girls $(70.58 \%)$ had positive family history of non-communicable disease (NCD).

\section{Discussion}

Several epidemiologic studies in Asian populations including Chinese, Taiwanese, Indians, and Koreans have demonstrated higher amounts of body fat at lower BMIs and WC than Western populations. This leads to the greater prevalence of cardiovascular disease risk factors at lower BMIs in Asian populations than in Western populations (31).

In Sri Lanka, the prevalence of obesity and overweight has increased and shows regional variation. A survey done a decade ago showed the overall prevalence of overweight was $2.2 \%$ (4). Present study demonstrated the prevalence of obesity and overweight were $5.5 \%$ and $9.4 \%$ respectively.

Children from different populations vary in their rate of proportional growth and in fat content as ethnicity influences body composition $(5,32,33)$. The prevalence of abdominal obesity was found to be $16.7 \%$ in 1500 Egyptian males and females aged 11-19 years according to WHtR (34). Study done in UK children in 1997 reported WHtR exceeded 0.50 in $11.7 \%$ of adolescent girls aged 11 16 years (26). In Swedish study girls aged $15.6 \pm 0.4$ years, high-risk WC was detected in $30.1 \%$ of subjects (35). 


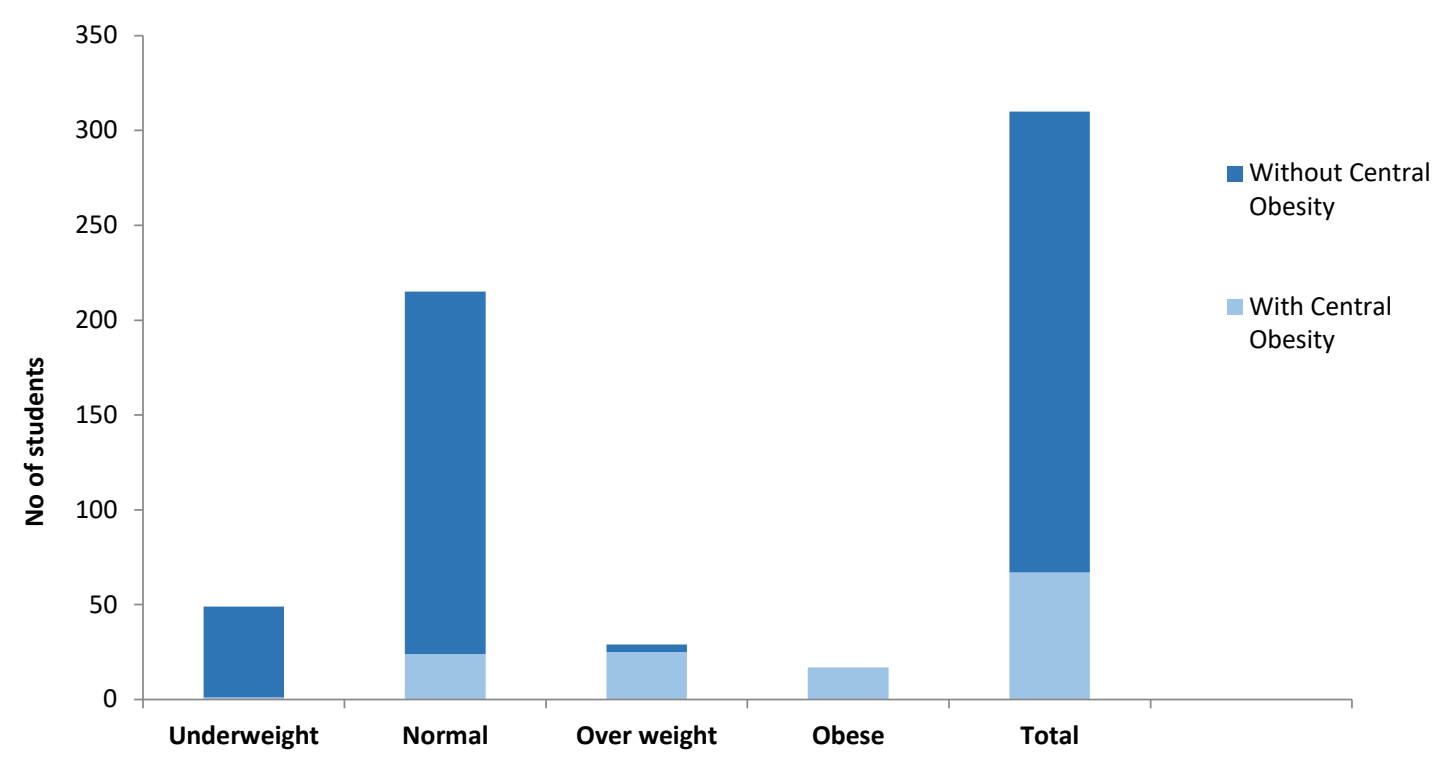

Figure 1: Number of girls with and with-out central obesity (Waist-height ratio $>0.5$ ) among different body mass index group $(P=0.0001)$

In a cohort of Iranian girls (14-17 years old), 18.2\% were centrally obese (36). The overall prevalence of central obesity in our sample was $21.6 \%$. Even among the girls who were categorized as normal-weight based on BMI, $11.16 \%$ had central obesity.

Majority of the girls who were obese had positive family history of non-communicable disease (NCD) (70.58\%). There is a significant correlation with central obesity and BMI. A high prevalence of central adiposity in our population is of concern as it increases the risk for obesity-associated morbidity and mortality in children and adults.

\section{Limitations}

This study was conducted in a single school, may not represent the whole adolescent population in the community.

\section{Conclusion}

Our study shows a high prevalence of overall and central obesity in adolescent girls. We emphasize the need for further large-scale surveillance programs on a randomized cluster samples representing whole eastern province and preventive strategies in our population to reduce the incidence of obesity.

\section{Acknowledgement}

We are grateful to all the students and teachers of the school \& Medical students for their support and cooperation. 
1. Wang Y, Lobstein T. Worldwide trends in childhood overweight and obesity. Int J PediatrObes. 2006; 1:11-25.

2. Maiti S, De D, Ali KM, Bera TK, Ghosh D, Paul S. Overweight and Obesity Among Early Adolescent School Girls in Urban Area of West Bengal, India: Prevalence Assessment Using Different Reference Standards. International Journal of Preventive Medicine. 2013;4(9):1070-1074

3. Zabeen B, Tayyeb S, Naz F, et al. Prevalence of obesity and central obesity among adolescent girls in a district school in Bangladesh. Indian Journal of Endocrinology and Metabolism. 2015;19(5):649-652.

4. Jayatissa R, Ranbanda RM. Prevalence of challenging nutritional problems among adolescents in Sri Lanka. Food and Nutrition Bulletin. 2006: 27: 153-60.

5. Wickramasinghe VP, Lamabadusuriya SP, Atapattu N, et al. Nutritional status of schoolchildren in an urban area of SriLanka. The Ceylon Medical Journal. 2004; 49: 114-8.

6. KSH desilva, VP Wikramasinghe, IMA Gooneratne. Metabolic consequences of childhood obesity - a preliminary report. Ceylon medical journal. September 2006; vol 51, No 3.

7. Magnussen CG, Koskinen J, Chen W, Thomson R, Schmidt MD, Srinivasan SR, Kivimäki M, Mattsson N, Kähönen M, Laitinen T, Taittonen L, Rönnemaa T, Viikari JS, Berenson GS, Juonala M, Raitakari OT. Pediatric metabolic syndrome predicts adulthood metabolic syndrome, subclinical atherosclerosis, and type 2 diabetes mellitus but is no better than body mass index alone: the Bogalusa Heart Study and the Cardiovascular Risk in Young Finns Study.Circulation. 2010 Oct 19; 122(16):1604-11.

8. WHO (2007) World Health Organization growth reference data for 5-19 years.

9. Kuczmarski RJ, Ogden CL, Guo SS, Grummer-Strawn LM, Flegal KM, Mei Z, Wei R, Curtin LR, Roche AF, Johnson CL. 2000 CDC Growth Charts for the United States: methods and development. Vital Health Stat 11. 2002 May; (246):1190.

10. Freedman DS, Mei Z, Srinivasan SR, Berenson GS, Dietz WH. Cardiovascular risk factors and excess adiposity among overweightchildren and adolescents: the Bogalusa Heart Study. J Pediatr. 2007 Jan; 150(1):12-17. e2

11. DeOnis M, Martínez-Costa C, Núñez F, Nguefack-Tsague G, Montal A, Brines J. Association between WHO cut-offs for childhood overweight and obesity and cardiometabolic risk.Public Health Nutr. 2013 Apr; 16(4):625-30.

12. Taksali SE, Caprio S, Dziura J, Dufour S, Calí AM, Goodman TR, Papademetris X, Burgert TS, Pierpont BM, Savoye M, Shaw M, Seyal AA, Weiss R. High visceral and low abdominal subcutaneous fat stores in the obese adolescent: a determinant of an adverse metabolic phenotype. Diabetes. 2008 Feb; 57(2):367-71.

13. Nambiar S, Hughes I, Davies PS. Developing waist-to-height ratio cut-offs to define overweight and obesity in children and adolescents. Public Health Nutr 2010; 13:1566-74

14. Higgins M, Kannel W, Garrison R, Pinsky J, Stokes J 3 rd. Hazards of obesity - The Framingham experience. Acta Med Scand Suppl 1988; 723:23-36.

15. Hsieh SD, Muto T. The superiority of waist-to-height ratio as an anthropometric index to evaluate clustering of coronary risk factors among non-obese men and women. Prev Med 2005; 40:216-20.

16. Bosy-Westphal A, Geisler C, Onur S, Korth O, Selberg O, Schrezenmeir J., Value of body fat mass vs anthropometric obesity indices in the assessment of metabolic risk factors. Int J Obes (Lond) 2006; 30:475-83.

17. Srinivasan SR, Wang R, Chen W, Wei CY, Xu J.Berenson GS. Utility of cardiovascular risk profile among normal weight younger adults (from the Bogalusa Heart Study). Am J Cardiol 2009; 104:721-4.

18. Hsieh SD, Yoshinaga H. Abdominal fat distribution and coronary heart disease risk factors in men-waist/height ratio as a simple and useful predictor. Int J ObesRelatMetabDisord 1995; 19:585-9.

19. Hsieh SD, Yoshinaga H. Waist/height ratio as a simple and useful predictor of coronary heart disease risk factors in women. Intern Med 1995; 34:1147-52.

20. Lee JS, Aoki K, Kawakubo K, Gunji A. A study on indices of body fat distribution for screening for obesity. Sangyo EiseigakuZasshi 1995; 37:9-18.

21. Ashwell M, Lejeune S, McPherson K. Ratio of waist circumference to height may be better indicator of need for weight management. BMJ 1996; 312:377.

22. Sardinha LB, Santos DA, Silva AM, Grøntved A, Andersen LB, Ekelund U. A Comparison between BMI, Waist Circumference, and Waist-To-Height Ratio for Identifying Cardio-Metabolic Risk in Children and Adolescents. Buzzett R, ed. PLOS ONE. 2016;11(2): e0149351. doi:10.1371 
23. Cardiometabolic risk assessments by body mass index z-score or waist-to-height ratio in a multiethnic sample of sixthgraders.Kahn HS, El ghormli L, Jago R, Foster GD, McMurray RG, Buse JB, Stadler DD, Treviño RP, Baranowski T, HEALTHY Study Group.J Obese. 2014; 2014:421658.

24. Linking definition of childhood and adolescent obesity to current health outcomes.Adegboye AR, Andersen LB, Froberg K, Sardinha LB, Heitmann BL, Int J PediatrObes. 2010 Apr; 5(2):130-42.

25. Hara M, Saitou E, Iwata F, Okada T, Harada K. Waist-to-height ratio is the best predictor of cardiovascular disease risk factors in Japanese schoolchildren. J AtherosclerThromb 2002; 9:127-32.

26. McCarthy HD, Ashwell M. A study of central fatness using waist-to-height ratios in UK children and adolescents over two decades supports the simple message - 'Keep your waist circumference to less than half your height'. Int J Obes (Lond) 2006; 30:988-92.

27. Kahn HS, Imperatore G, Cheng YJ. A population-based comparison of BMI percentiles and waist-to- height ratio for identifying cardiovascular risk in youth. J Pediatr 2005; 146:482-8.

28. Savva SC, Tornaritis M, Savva ME, Kourides Y, Panagi A, Silikiotou N, et al. Waist circumference and waist-to-height ratio are better predictors of cardiovascular disease risk factors in children than body mass index. Int $J$ ObesRelatMetabDisord 2000; 24:1453-8.

29. Maffeis C, Banzato C, Talamini G; Obesity Study Group of the Italian Society of Pediatric Endocrinology and Diabetology. Waist-to-height ratio, a useful index to identify high metabolic risk in overweight children. J Pediatr 2008; 152:207-13

30. Browning LM, Hsieh SD, Ashwell M. A systematic review of waist-to-height ratio as a screening tool for the prediction of cardiovascular disease and diabetes: 0.5 could be a suitable global boundary value. Nutr Res Rev 2010; 23:247-69.

31. Wildman RP, Gu D, Reynolds K, Duan X, He J. Appropriate body mass index and waist categorization of overweight and central adiposity among Chinese adults. Am J ClinNutr 2004; 80:1129-36.

32. McCarthy HD, Jarrett KV, Crawley HF. The development of waist circumference percentiles in British children aged5.016.9 y. Eur J ClinNutr 2001;55:902-7.

33. Tybor DJ, Lichtenstein AH, Dallal GE, Daniels SR, Must A. Racial differences in central adiposity in a longitudinal cohort of black and white adolescent females. BMC Pediatr 2010; 10:2.

31. Abolfotouh MA, Sallam SA, Mohammed MS, Loutfy AA, Hasab AA. Prevalence of od pressure and association with obesity in egyptian school adolescents. Int J Hypertens 2011; 2011:952537

32. Ortega FB, Ruiz JR, Sjöström M. Physical activity, overweight and central adiposity in Swedish children and adolescents: The European Youth Heart Study. Int J BehavNutrPhys Act 2007; 4:61

33. Rafraf MA, Mohamadi EB, Gargari BP. Prevalence of overall and abdominal obesity among adolescent high school girls 